the former operation was performed in this country by $\mathrm{Mr}$ Mitchell Henry many years ago, and which resulted in a rapidly fatal issue, I was led to try the milder measures I hav described; and as an alternative of the more severe operations for the relief of this troublesome affection the plan is one which is, I think, deserving of a more extended trial. I would only further suggest that it should be practised cautiously.

Hanler, Staffordshire.

\section{CASES OF SUDDEN OBSTRUCTION OF THE CESOPHAGUS.}

BY PUGIN THORNTON,

SCRGEON TO THE ST. MARYLEBONE GENERAL DISPENSARY.

LAST year two cases of stricture of the cesophagus came under my notice, in both of which a sudden obstruction to the passage of food was the first symptom of disease. In the first case the affection proved to be of a benign nature, in the second malignant. I venture to bring these cases forward because sudden and extreme dysphagia, attacking a person apparently in good health, is a rare condition, and one which must affect a surgeon's ability to determine upon the nature of an osophageal stricture. Sir James Paget, who saw the second case, tells me that he has never before known sudden obstruction to the passage of food to be the first symptom in cancerous stricture of the gullet. The first case is also of much interest, because in most respects it resembled one of malignant disease.

CASE 1.-Mrs. - o over sixty years of age, was sent to to me by Mr. W. H. Evans, of the Finchley-road. Mrs. informed me that four days previously, during dinner, a piece of meat had stuck in her throat, and that it was with great difficulty she had managed to pass it down, that for some hours after the accident she had been unable to swallow anything, and then, and till the time she saw me, she had only been able to take liquids drop by drop. The patient was in good health at the time of the accident and had never before found difficulty in taking food She had been apt, she acknowledged, to hurry through her meals, although unable to masticate her food properly, her teeth not being in good order. Since the accident Mrs. - had felt continuous pain in the right ear, and had been troubled with a constant collection of frothy phlegm. In swallowing she also felt pain between the cricoid and sternal cartilages. Her expression was anxious. She was very thin, but was not aware that she was thinner than she had been for years. The larynx and surrounding parts were normal in appearance. Mr. Erans had written to say that he had been unable to pass an instrument through the stricture, and I also met with the same difficulty, the constriction being opposite the cricoid cartilage. At first beginning with a large-sized bongie, I made steady and protracted pressure on the stricture, and I then tried quickly through some of the smaller instruments. On March 13th I could pass a bougie down the left side of the gullet, but on the right side the cesophageal canal was still firmly closed. Mrs. ㄴ.. had been able to take small pieces of dry bread, and could now drink without stopping. The pain in the right ear continued, but was not so severe, and the anxious expression in her face liar disappeared. This patient made a complete recovery, and has remained free up to the present time from any relapse, although she has since, I have heard, been through a severe attack of pneumonia.

Cise 2.MIajor —_, aged sixty-two, consulted me on Harch 23rd, 1880, on account of dysphagia which had tcoubled him for three weeks. When he came to see me he iil mable to take solid food, and liquids only with diiii ulty. He said that the stoppage had come on suddenly filuing a meal, when he was apparently quite well. Finding Limself unable to take anything he became very nervous, utel for some hours would not make any further attempt to wallow, and when he tried he could only manage a tea-romful of lluid at the time. On examination I found a xil cture at the apper part of the lower third of the cesophasus, througri which I could not pass the smallest-sized nguile. The patient was well nourished in body, nor had 11t niticed that he had lost flesh. His face was anxious, but fresented no appearance of a cancerous cachexia. There was a murmur to be heard in the cardiac region, which, on consultation with Dr. Ringer, this physician pronounced to be aortic, and not aneurismal. For diagnostic purposes I asked this gentleman to pay me a second visit in a fortnight's time. I afterwards learnt that he was taken to Sir James Paget. He died a few weeks later.

At the post-mortem examination Dr. Hodson, of Bishop's Stortford, has informed me that he found a cancerous stricture, annular, but not complete, about one inch and a half above the cardiac orifice.

What the condition of the csophagus was in the first case it is hard to say. It could scarcely be that the cricoid cartilage was diseased, or the patient would have felt pain on external pressure, and most probably some mischief would have been detected in the laryngeal examination. If we say that it was a case of spasmodic stricture it is difficult to account for the fact that on passing a bougie at the patient's second visit an obstruction was met with on the right side of the gullet, and not on the left. One would think that the closure of the csophageal walls in the case of a spasmodic stricture would either give way all at once or equally from the centre of the canal, unless, indeed, in this instance a very slight and old-standing constriction of the mucous wall on the right side of the cosophagus was present at the time of the accident. Undoubtedly the circumstance of finding a complete stricture, apparently organic, in an old woman, attended with the symptom of constant pain in the right ear (the side, let it be noted, the stricture lasted the longest), and with the presence of a quantity of frothy phlegm, pointed in a great measure to the affection being of a cancerous nature.

Mr. Power, in 1866, related in THE LANCET (vol. i., p. 252) a case of stricture in which the patient died of inanition, but that on a post-mortem examination he found a perfectly natural condition of the oesophageal walls. In this case the difficulty of swallowing came on gradually, and a large-sized bougie was on one occasion passed by force through the stricture. By both patients I was asked to give a decided diagnosis. In both instances I was unable to do this. With regard to the case of Mrs —, I explained that the nature of the illness could not at once be determined upon, but could only be cleared up by time; that although the condition of the patient was undoubtedly very serious, yet, at the same time, from the abnormality of the symptoms, there was reason for saying that the case should not be considered as hopeless. In the second instance, although one had the experience of the case of Mrs. - - there was more reason to suspect that the stricture was of a cancerous nature on account of its position, but here again it was difficult to account for the suddenness of the attack, coupled with the absence of other signs, and the previous good health of the patient. Perhaps the proper course for clearing up the diagnosis in each case would have been to attempt to pass a bougie whilst the patient was under chloroform.

Devonshire-street, Portland-place.

\section{PHANTOM TUMOUR.}

\section{BY P. D. M A L L I K, M.B.}

ON Dec. 3rd, 1880, I was called to see a case of spurious pregnancy. The patient's history was as follows :-

M_-, aged seventeen, married. No children, no miscarriages. Menses arrested since July, 1879. General health good. No family history of hysteria. A month after the cessation of her menses she had nausea and the usual sympathetic disturbances of pregnancy. About the second month the breasts became increased in size and tender, and afterwards became much larger and firmer; blue veins were seen crossing them. The nipples became turgid, and the changes in the areolic were marked, and exactly resembled those seen in a case of true pregnancy. About the lifth month the abdomen was found to te prominent and enlarged. Quickening was perceived by the patient, and, what is more strange, apparent fotal mutions were observed. The patient was pronounced pregnant, and although she was suffering at the time from irregular attacks of intermittent fever, yet, according to the prejudices still unfortunately prevalent among a large section of the native community, she was not placed under 